\title{
The new driving and faults solving simulator for the Madrid light rail system
}

\author{
L. M. Gutierrez, J. M. Mera, E. Castellote, A. Garcerán \& F. Ariza \\ CITEF, Universidad Politécnica de Madrid, Spain
}

\begin{abstract}
The new Light Rail's Driving Simulator, presented in this paper, is equipped with the tools needed to train staff to drive the new rolling stock and control traffic on the new Madrid Light Rail lines ML1, ML2 and ML3.

In the capacities granted to the set of simulators not only is the reproduction of the whole trains emphasized, but also the capacity to make training exercises with train failures (approximately 400 different types) or incidences (approximately 50 different types).
\end{abstract}

Light Rail's new Driving Simulator represents an enormous step forward in training capacity through simulated environments allowing, for the first time, comprehensive training for staff when carrying out joint exercises. The full Simulator integrates several different stations:

- One Instructor Station.

- One Real Driver's Cab: a scale model of a car with integrated real equipment, a four channel visual system and an environmental audio system.

- 12 Driver's Training Station: a virtual simulator with basic real controls.

- 12 Traffic Control Inspector Station (integrated in the Driver's Training Station).

These training stations allow the uninterrupted running of exercises in:

- Joint driving of coupled Train Units.

- Joint or individual driving of uncoupled Train Units.

- Coupling and uncoupling units.

- Joint driving and operating exercises where there may be simultaneously: two drivers in two train units, a Traffic Control Inspector.

The simultaneous use of these stations enables all the staff involved in operating a line to be reproduced; this leads to the work teams becoming integrated so that each person taking part in a joint exercise can understand the problems faced by the other workers.

The Light Rail simulators are integrated as a whole to provide centralised training management, resulting in a single source of information for the training plans and training sessions carried out by trainees in the different simulators. This means that there is a single comprehensive training control tool available.

The developed model allows the visualization of the state for the different electrical and pneumatic circuits that constitute the trains. This allows the students to understand the internal operation of the train and the behaviours of the vehicles in the different failures that can be displayed.

Keywords: computer-based training, driving simulation. 


\section{Training requirements and needs}

During the last few years Metro de Madrid's railway and light rail network has seen strong growth while its fleet of rolling stock has been renewed and expanded to satisfy new operating needs. This growth in the network and rolling stock has also been associated with an internal structural change aimed at adapting to the company's modernisation.

These factors have led to training procedures being reorganised to adapt them to two fundamental facts: an increase in the number of staff who need to be trained in network maintenance, and a reduction in the number of staff trained in training compared to the staff requiring this training.

After an internal review it was decided that the new training requirements had to be addressed by introducing specific training tools that together with traditional training procedures would establish a new training model in accord with the company's new current circumstances. This internal review sought to complete the training plans by finding a solution to the most usual training problems (such as a lack of practice when faced with rarely occurring situations), as well as the main problems to be found in everyday operations (communication problems, identifying failures...).

The result of the review was translated into a simulator possessing specific features for addressing the main training problems.

\section{Simulator concept}

The Simulator for Metro de Madrid's Light Rail series consists of eight work stations called Pre-Training Stations (PFP), a central Simulation Station mounted on a mock-up of a Real CITADIS series Cab, an Instructor Station and a group projection screen. In addition, it also contemplates the existence of four On-line Training Stations. All these elements allow simultaneous training sessions for up to thirteen trainees divided among the different stations, as well as an Instructor to perform control tasks and classroom management.

The simulation position in the Real $\mathrm{Cab}$ incorporates an actual CITADIS series real driver's cab appropriately sensored and equipped with full functionality for all its components. Fitted at the front and sides of the Real Cab is the projection system for the visual environment that simulates the driving scenario of the different lines of Metro de Madrid's Light Rail. The special shape of the driver's cab of Light Rail's units requires the use of additional side projectors if an adequate display of the visual environment is to be had from the driver's seat. The reproduction of real cab sounds is achieved by a sophisticated 5.1 audio system that manages to reproduce sounds according to their location. The whole is completed by a closed circuit camera that enables the Instructor to uninterruptedly observe the actions taken by the trainees in the driver's cab.

The simulator's central control station is the Instructor Station. It is designed to provide the Instructor with all the tools needed to carry out the Training and Control tasks. It comprises four monitors arranged as follows:

- A dual-screen system for the Station user interface from which all the work is done during the Training sessions. 
- $\quad$ A screen to display the visual environment during exercise monitoring by the Instructor.

- A screen for displaying the images from the closed circuit camera in the Real Cab.

Two computers lend support to the Training Station, both when running the management application (HECOFORM), and when providing the Training and User Data Base service, which centralises all the information from the simulation centre.

The Pre-Training Station and the On-line Training Station let trainees run the exercises included in their Training Plans in a virtual environment that represents the real driver's cab of Light Rail's units by means of photorealistic computer models. Two computers, one for the models and one for the visual, and two viewing screens, serve these stations. They also incorporate headphones that reproduce the actual train sounds. The so-called Pre-Training Stations are those in the simulation room itself, while the so-called On-line Training Stations are intended for training tasks distributed round any parts of Metro de Madrid's network, although construction and operation-wise the stations are identical.

Finally, the group projection screen provides a useful means for the joint assessment and analysis of procedures, mainly in collaborative exercises.

\subsection{Instructor station}

The Instructor Station or Instructor Position is, together with the Real Cab, the main element of the Simulation Centre. The tools and functionalities fitted allow it to carry out an exhaustive control of the tasks performed during the learning sessions. The central idea behind the design of the Instructor Station was to successfully provide the Instructor with tools that would enable them to expand their control and management capacity over a Training classroom. Tasks that need be done on different platforms in other simulators or which are simply not possible are centralised in the Instructor Station.

The system has been designed so that the Instructor may comfortably and uninterruptedly carry out all training-related activities, ranging from classroom control and management at a hardware and software level, passing through the creation and design of the different Training Plans, the dynamic launch of exercises, failures and incidents, up to advanced tasks like monitoring Stations and configuring complex exercises.

For these tasks to be properly performed the Instructor Station has been equipped with a series of capacities that empower the Instructor to:

- Create exercises, lessons and courses that can be grouped together in Training Plans that will be subsequently assigned to trainees.

- To carry out maintenance of the data stored in the Training Data Base system.

- Control the state of the different stations under their control in real time by advising the Instructor when a trainee connects, runs or stops their exercises. 
- Carry out maintenance tasks on the Real Cab.

- Access images from the camera for viewing in the Real Cab.

- Actively intervene in the trainees' exercises either to change their characteristics in real time by means of failures and incidents, or directly by operating elements of the train or the infrastructure itself.

- Configure complex collaborative exercises.

It is precisely these last two functionalities that represent a real leap forward compared to the traditional concept of railway/light rail simulation systems; these will deserve a special mention further on.

\subsection{Pre-training stations}

The Training Stations comprise the training posts for trainees in Metro de Madrid Light Rail's simulator training classroom. Each of the Stations lets the trainees carry out the exercises and training tasks set out in the Training Plans assigned.

These stations provide the trainee with a driving environment like that to be found in Light Rail's CITADIS series units, made up of two viewing screens mounted vertically. The lower screen displays the AUTOFORM training control application via which trainees can access their Training Plans and control running the exercises. During a standard exercise run this screen displays a photorealistic representation of a CITADIS driver's cab with all the elements to be found in an actual unit. In order to display the elements located in other parts of the unit, additional screens are shown. The upper screen shows the visual corresponding to the actual environment of the line being travelled.

To refresh their knowledge of the unit's internal workings, the trainee can access the cabinets of the different equipment on the train and the schematic diagrams of various elements and basic circuits, as well as making dynamic changes to the driver's cab.

The Training Stations can be shown in two formats.

- The basic format is a completely virtual simulation environment where all the operable train elements are shown using a photorealistic representation.

- The so-called "minidesk" format offers greater immersiveness since inserted into the work desk are the basic train control elements such as the control handle, emergency stop button and door and driving mode controls. These controls are embedded in the very same positions as in a real train cab and moreover, are identical to the originals. The remaining elements continue to be operable from the virtual environment.

The Training Stations, therefore, enable special exercises to be run that are aimed at training technical staff in the Control Station, the Interlocking Local Control Station or Line Technicians. In these cases, the visual display is adjusted to the requirements of each environment, but always showing a display that is 

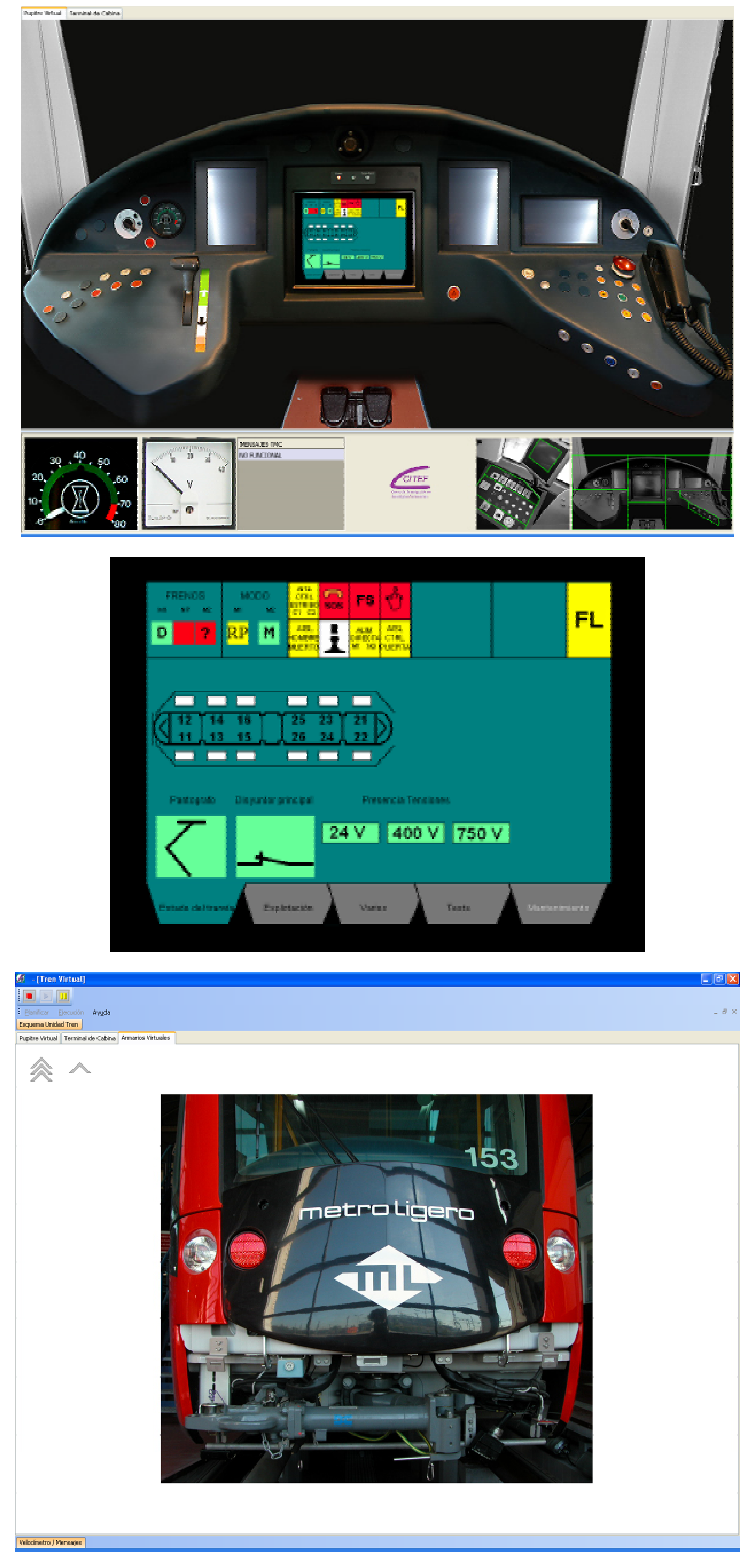

Figure 1.

identical to the real applications. To this end, a model has been developed that looks the same as the real station that it is intended to reproduce, both graphically and operatively and can be operated either by a mouse or commands written by the operator, as appropriate to each station. 


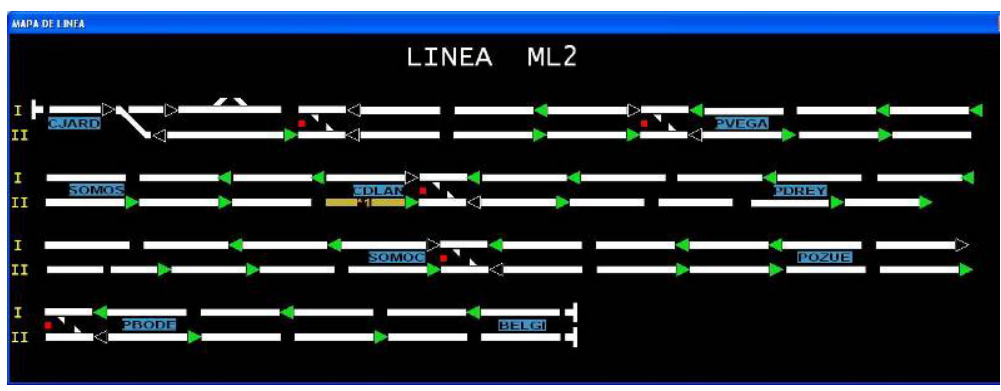

Figure 2.

\subsection{On-line training stations}

Identical to the Pre-Training Stations, these On-Line Training Stations respond to the concept of "distributed simulation".

Constructively, these stations are no different from any Pre-Training Station except in their location. Easily portable, they can be placed at any point of Metro de Madrid's network.

They were designed out of a desire to make training by simulation a directly available tool in any part of the network.

\section{Systems modelling}

\subsection{Train model}

The mathematical train model has been made from the original plans provided by ALSTOM. By digitalising these plans and using the editing tools designed by CITEF, every train element has been transferred to the simulation model resulting in an appropriate level of realism that makes real train behaviour practically indistinguishable from that of the simulation model.

The starting point to reproduce the behaviour of the CITADIS built by ALSTOM consisted in implementing all the electric circuits shown on the plans (a set of 50 plans per car), which were then subsequently subjected to simulation logic to determine the flow of electric current through the circuits. Every possible type of voltage and the components required to connect them to one another (converters, inverters) were borne in mind and simulated, from the DC high voltages supplied to the pantograph to the low voltages of warning lights and push buttons.

A series of on-board electronic equipment distributed throughout the train forms part of the electrical circuits (various electronic cards, robots, ATP equipment...), that is also simulated on a logic level, enabling the correct behaviour of the outputs of these circuits to be modelled through their inputs, as well as the appropriate timing and the information obtained from other electronic equipment by means of communication buses which have also been included in the model. 
Metro de Madrid places great emphasis on training its drivers in troubleshooting the various failures and incidents that can arise during normal operation, in order to minimise the stopping times and delays this causes. To do this, and using the highest level of model realism, a large number of failures have been included (400) that affect the different circuits and equipment, and incidents (50) that range from people being trapped in the doors to voltage drops in the catenary.

Closely linked to the train simulation is the train's dynamic model, which has been developed from the actual train specifications supplied by the manufacturer. Examples of these data are the traction and braking curves, train weight, accelerations, etc.

The efforts made to fit out the train model with this level of detail by modelling the electrical and electronic layouts have resulted in a series of benefits:

- Simulation behaviour identical to that of the real train, attaining a degree of realism in train response to trainee actions that is impossible to obtain with any other type of modelling (a conditional simulation, for example.).

- Since there is an electrical simulation as part of the train model, it is possible to show a set of schematic diagrams where trainees can see the real-time working of any electrical circuit simulated, which gives the simulator new training possibilities.

- Likewise, as all the elements located in the different electrical circuits of the train are modelled as part of the simulation, failures can be simulated for every one of these elements in the diagrams, be they contacts, relays, or even electric batteries. The typical failures of these elements are usually short circuits, driving errors, contact interlockings, etc.

- As a result of all the above, a tool is available that is not only focused towards driver training, but also aimed at teaching engineers and maintenance workshop staff.

\subsection{Infrastructure modelling}

Aimed at customising staff training to the peculiarities of Metro de Madrid's network, Light Rail's three lines have been modelled for this simulator taking the actual signposting and signalling plans. Since the project began two years before the line was commissioned, it has developed in parallel to the line construction, which means that changes have had to be made to the model to fit in with the changes made to the building plans of the infrastructure.

Due to the particular features of the project, and the simultaneous coming together of railway, light rail and road signs and signals, reproducing the infrastructure has proved to be a real technical challenge.

One peculiarity should be pointed out; the coexistence on Light Rail's line 1 of a double signalling system: 
- The tunnel sections have a railway signalling system with ATP and the track is divided into track circuits where continuous information is being transmitted to the trains.

- The outside section has a tram protection system only in the points zones where there are track circuits and a road protection system in the pedestrian and car crossing zones

It is precisely the ATP system that has given the infrastructure modelling a special character (similar to the actual line itself) by inserting a large number of special features that make the most of the system (neutral zones, transitions, systems synchronisation...).

The model infrastructure was completed by inserting incidents and failures, mainly taking account of three large groups:

- Different signal component failures such as signs, point motors, track circuits, etc.

- Incidents on the length of the line such as obstacles on the track, works on the line, etc.

- Incidents related to the movement of cars and people that cross the track and remain there preventing the train from passing.

A correct use of the exercise planning tools therefore means that most of the situations driving staff can be involved in during their everyday activity on the lines can be reproduced in the infrastructure model.

\subsection{Road traffic}

Light Rail is a new operating concept introduced into Metro de Madrid's network that requires the need to use simulators that precisely model the environment in which the real train will operate.

The main difference between Light Rail and Metro de Madrid's other lines is that the former has surface sections, with level crossings with road traffic and pedestrians crossing. This has to be borne in mind in the simulator in order to provide drivers with the training needed to do their job properly.

To obtain an environment that is as similar as possible to the real line, a road traffic model has been developed containing the artificial intelligence necessary for the simulated vehicles to behave as in real life, by observing the Highway Code in force.

Thus, the model is capable of making the vehicles move while taking account of the real traffic events in a city, such as traffic-lights and road signs, but obviously never failing to respect the pedestrians moving in the city model and the other simulated vehicles.

Regarding this last point, it should be pointed out that unlike in other simulators, the pedestrians are not static figures waiting for the next train to arrive in order to get on or off, an action that is indeed reflected in this simulator, but individual figures that interact with their surroundings and are capable of moving throughout the city, crossing at traffic-lights, invading the rail track or walking along the different streets. 
For the whole to work correctly, the way the different road traffic-lights work has been modelled together with how they interact with the track signs and signals, as in this operation, the train always has priority over surface traffic, although both types of signs and signals have a joint logic aimed at optimising the light rail operation and the circulation of vehicles and pedestrians.

The result of all the above has been a highly immersive environment adapted to the features of the rolling stock so that trainees quickly forget they are in a simulator and detect the specific operating characteristics they will be subjected to when they drive real train units.

\subsection{Rail traffic}

The rail traffic model in this simulator aims to reproduce the running and operation of an actual line, therefore it must adapt to the signal and signposting systems on the line. The model used provides for the use of independent models of the trains comprising the traffic, which are therefore scaled-down models of the full simulator model.

Each individual train model complies with the actual signalling and signposting systems on each line, which means it makes specific decisions for each line. For example, on the sections where the train is driven by sight and there is no signal to prevent two trains from being in the zone, special supervision is used to prevent a collision between two trains, while if there is a sign, the train approaching it must obey it.

Due to the complexity of the project by including interactions between pedestrians, cars and trams, the crossings with pedestrians and cars must comply with the strict the rules of behaviour actually in force. Each of these crossings is independently controlled by algorithms that analyse and govern the state of the signals and signs on the crossing, giving priority, as is the actual situation, to Light Rail, as there are train approach balises that facilitate the train's passage whenever possible. The train models considered also comply with these rules and observe the visual signals that would be perceived by a driver from the driver's seat.

\section{Innovation and new training features}

\subsection{Autonomous training system}

The system has been designed to implement the Training Plans for trainees so that both locally and when interconnected with the Training Department's own systems, the Training and User Data Base system centralised in the Instructor Station computer will allow those in charge to carry out all the design, control and consultation tasks of the trainee Training Plans and see their training history. The system lets the contents be defined on an exercise, lesson and course level in line with the training needs of each particular moment.

Reports can be prepared and the simulation results exported for subsequent processing by Metro de Madrid's Training Department staff. 

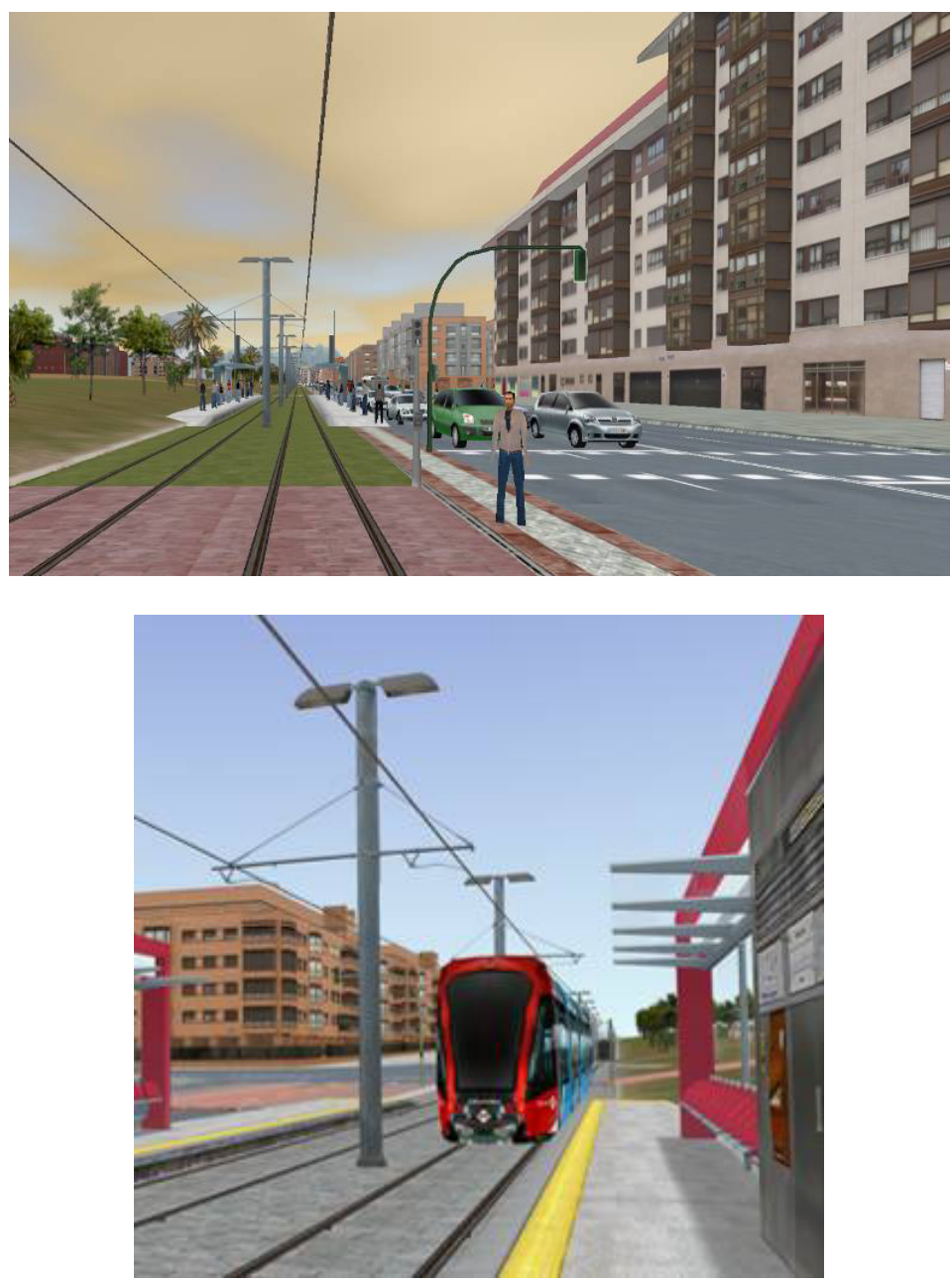

Figure 3.

\subsection{Distributed training}

Using the On-Line Training Posts enables an easily transportable training tool to be available that can be set up in the places closest to the driving staff. In this way, the drivers, technicians and staff of Metro de Madrid can have access to the benefits of training in a simulation environment without having to attend a training centre. With tailor-made pre-set exercises, in-situ training can be provided thanks to this concept, thereby allowing driving staff to make a more efficient use of their free time by being able to make consultations and/or do training practice without having to make a journey that limits staff operating capability. 


\subsection{Active intervention and collaborative training}

As described above, there are two features that form part of the Simulator's capacities and which deserve special attention as they represent a considerable step forward in extending current simulation system functionalities. These are:

- Intervention by monitoring.

- Simulation of complex collaborative exercises.

Thanks to monitoring, from the Instructor Station the Instructor can intervene in an exercise being run. The training control tool (HECOFORM) installed in the Instructor Station allows one of the Stations running an exercise in the classroom to be "captured" so it can be monitored. The Instructor can view the entire environment of the station monitored from the Instructor Station and follow the trainee's actions at every instant. There are two types of monitoring:

- Passive: the Instructor simply navigates the trainee's environment to see what actions are taken. The elements cannot be operated. The Instructor's navigation remains unnoticed by the trainee being monitored.

- Active: the Instructor can observe and at the same time operate the train elements of the trainee being monitored. Likewise, the Instructor's navigation remains unnoticed by the trainee. This allows the Instructor to interact directly on the trainee's exercise, which is sometimes valid for developing certain aspects of training.

The Instructor's capacity to intervene in the exercise is not limited to operating the train but they can also:

- Activate and deactivate failures and/or incidents to the train and/or infrastructure.

- Change the levels of traffic as well as the field elements, but always under the logic control of the real restrictions of the interlocking.

- Individually change the behaviour of the automatic trains.

- Introduce changes to the environmental conditions.

- Alter the level of passengers and moving traffic.

Simulating complex collaborative exercises depends on the capability to design scenarios where additional driven trains are involved, possibly together with specific Operation Stations, conducting specific manoeuvres. These scenarios are designed by the tool at the disposal of the Instructor in the Instructor Station enabling exercises such as the following to be done:

- Exercises with several trains driven simultaneously from several stations.

- Exercises to couple and uncouple trains.

- Exercises for driving via an intermediate cab.

- Exercises for assistance between units.

- Exercises with the participation of the Control Station, Interlocking Local Control Station and/or Line Technician Station.

With the system implemented in Metro de Madrid's Light Rail Simulator, a suitably trained Instructor can configure a simulation classroom that virtually 
reproduces the operations of a section of the Metro network. For example, let us imagine a classroom with four Training Stations plus the Real Cab, all immersed in the same exercise, on a line with peak-time traffic where two of the trainees are driving trains on the same line; one of them in the Real Cab, the third trainee acts as Control Station, the fourth controls an Interlocking Local Control Station while the last takes part as a Line Technician. The actions from the Control Station or the Local Control Station are applied immediately to all the participants. Meanwhile, in these circumstances the Instructor can launch a train failure while everyone is interacting jointly...

By processing these complex situations, training issues can be addressed that used to be clearly outside the usual training spheres of traditional simulator training.

\section{Conclusions}

Developing the project in parallel with the construction of the infrastructures and the rolling stock resulted in some considerable difficulties for the project design. However, once this handicap had been overcome in the critical stages of the project, it enabled Metro de Madrid training staff to speed up the training tasks required to bring the new infrastructures into service. This meant that the staff needed were ready to operate the Light Rail correctly even before the line works were completed and the rolling stock fine-tuned, thereby enormously optimising the process of bringing the line into service.

In addition, the conception of Light Rail's new simulator with training stations for the different agents (drivers, line operators...) has enabled Light Rail's training staff to set up a specific Training Centre for the light rail subnetwork. This versatile configuration at both individual station level and as a whole for carrying out joint training tasks, together with the integration of all the staff being trained into a single classroom has meant that the training department's own resources have also been optimised. With this new Centre a minimum of qualified staff can carry out comprehensive training in the main events that can occur in the infrastructure from an operational point of view. The joint training tasks as well as the specific tools for each of the agents intervening in the operating tasks have increased the training quality to time ratio in addition to enhancing communications and relations between the different staff employed to run the railway sub-network.

Finally, it should be emphasised that the management and assessment capacities of the tools enable instructors to have greater control over trainee actions during training, as well as letting them detect any weak points in the courses given. In this way, and by using the On-Line Training Stations, the training system is completed with a new system of learning aimed at improving staff already qualified in aspects where a deficit of knowledge or practice has been detected. These staff can now complete this cycle in their usual place of work with the resulting optimisation of the human, technical and management resources required for this process. 


\section{References}

[1] 2Train: Training of Train Drivers in safety relevant issues with validated and integrated computer-based technology. (http://www.2train.eu)

[2] Training in the new driving and failures simulator of Metro de Madrid (http://library.witpress.com/pages/PaperInfo.asp?PaperID=18151)

[3] Simulation's definition at Wikipedia (http://en.wikipedia.org/wiki/ simulator)

[4] A Tour of the Amtrak Training Facility (http://www.weaverling.org /atc/sim)

[5] BEVAC Consulting Engineers (Train simulator for Moroccan National Railways) (http://www.bevac.be/simulator.htm)

[6] CFF Re460 simulator - Swiss railways Loc training simulator (in French) (http://home.urbanet.ch/urba1206/Trains/files/simu.htm)

[7] CFL 3000 - A locomotive simulator in Luxembourg (http://www.rail.lu/ cflsimulateur.html)

[8] Eurostar Train simulator - A training simulator for Channel tunnel train drivers (http://www.qnx.com/company/customer_stories/ss_206_2.html)

[9] INCERTRANS- various original old training simulators (Romania) (http://www.afer.ro/rom/SIUSI_Simulatoare_vehicule.htm)

[10] PZL Loc simulator- Railway simulator by the Polish company PZL. (http://www.ai.com.pl/en/products/ep09_ds.html)

[11] Simulator för spårburen trafik (SST) Swedish Simulator for Trackbased vehicles (http://www.it.uu.se/research/project/sst/api)

[12] Euskosim - Lander simulación (http://www.landersimulation.com/ index.php?id=29)

[13] Rotterdamse Metro (http://www.retmetro.nl/nl_msts_index.htm)

[14] Metro Bilbao - Simulator (http://www.metrobilbao.net/accesible/eng/ metro/simulador.html)

[15] Corys - Various Training simulators (http://www.corys.com/domaines/ railway-simulation.php)

[16] EADS - Train simulators (http://www.railway-technology.com/contractors/ professional/dornier)

[17] Krauss-Maffei Wegmann- Training simulators for military and civil vehicles (http://www.kmweg.com/gb/frame.php?page=44)

[18] Indra sistemas - Simuladores ferroviarios (http://www.indra.es/servlet/ ContentServer?pagename $=$ IndraES/Proyecto_FA/DetalleProyecto\&cid $=10$ $83830070898 \&$ pid $=1083830064940 \&$ Language $=$ es_ES\&opc $=$ Listado)

[19] FAAC Incorporated (http://www.faac.com/railsimulators.htm)

[20] ORTHSTAR (http://www.orthstar.com/modsim4.htm)

[21] Visual simulation at Valencia University (Visor de línea (http://robotica.uv.es/castellano/ARTEC/home.html\#Simulacion_civil)

[22] Onyx Real-Time Image Generation (http://www.futuretech.blinkenlights.nl/ onyxrtig.html) 